13,12

\title{
Электростатическая природа размерных зависимостей адсорбционных свойств нанопленок иттербия, выращиваемых на поверхности кремния: система $\mathrm{CO}-\mathrm{Yb}-\mathrm{Si}(111)$
}

\author{
(C) М.А. Митцев, М.В. Кузьмин
}

Физико-технический институт им. А.Ф. Иофффе РАН, Санкт-Петербург, Россия

E-mail: M.Mittsev@mail.ioffe.ru

(Поступила в Редакцию 4 февраля 2018 г.)

\begin{abstract}
Исследована адсорбция молекул СО на нанопленках иттербия различной толщины (от 1 до 16 монослоев). Изучены зависимости количества адсорбированных молекул СО (изотермы адсорбции) и работы выхода пленок иттербия от дозы монооксида углерода. Показано, что и количество адсорбированных молекул и работа выхода при равных условиях зависят от толщины нанопленок (размерный эффект). Установлено, что размерный эффект обусловлен электростатическим взаимодействием между локализованными на поверхности нанопленок электронами, осуществляющими связь молекул СО с поверхностью, и электронами проводимости иттербия. Это взаимодействие зависит от толщины пленок. Оно ограничивает количество молекул СО, которое может адсорбироваться на поверхности пленок при заданной их толщине.
\end{abstract}

DOI: 10.21883/FTT.2018.07.46133.024

\section{1. Введение}

В настоящее время уделяется значительное внимание изучению структур нанометрового размера $[1,2]$. В частности, значительное количество работ посвящено изучению адсорбционных свойств таких структур. При этом в значительной части из них в качестве адсорбата используется монооксид углерода (угарный газ СО) [3-8]. Недостатком этих работ является то, что в них не проводилось систематическое изучение типа связи молекел СО с поверхностью нанообъектов, размерных зависимостей адсорбционных свойств последних и возможного влияния адсорбата на свойства их объема.

В отличие от только что указанных исследований в работах авторов настоящего сообщения едва ли не основное внимание уделяется изучению природы адсорбционной связи молекул с поверхностью подложек и влиянию адсорбата на свойства объема нанообъектов. Так, в работах [9-11] было показано, что молекулы СО при адсорбции на нанопленках иттербия своими двумя неподеленными электронами образуют с поверхностью подложек донорно-акцепторную связь. Было показано также, что при толщине пленок иттербия от 1 до 16 монослоев адсорбция молекул СО сопровождается его переходом из двухвалентного состояния в трехвалентное.

Авторами настоящего сообщения было предположено, что отмеченные особенности систем СО-нанопленки иттербия должны сказаться на адсорбционных свойствах пленок. Поэтому целью настоящей работы было исследование зависимостей количества адсорбированных молекул СО от дозы монооксида углерода (изотермы адсорбции) для пленок иттербия различной толщины.

Другой задачей работы было изучить зависимости работы выхода указанных структур от дозы моноок- сида углерода и от количества молекул СО, которые адсорбированы на поверхности нанопленок, имеющих разную толщину. Предполагалось, что полученные данные дадут дополнительную информацию, необходимую для понимания природы адсорбционных характеристик изучаемых систем.

Наконец, третьей задачей работы было, используя ранее полученные результаты, а также экспериментальные данные настоящей работы, провести комплексный анализ процессов, происходящих при адсорбции молекул СО на поверхности нанопленок иттербия.

\section{2. Методика эксперимента}

Как уже указывалось, в работе исследовалась адсорбция молекул монооксида углерода на пленках иттербия нанометровой толщины (от 1 до 16 монослоев). Пленки создавались путем напыления иттербия на монокристаллические кремниевые подложки $\mathrm{Si}(111)$ при комнатной температуре (RT). Как было показано в нашей работе [12], такие условия дают возможность создавать пленки с достаточно высокой степенью однородности по толщине. Именно такие пленки необходимы для выполнения задач настоящей работы. Адсорбция молекул СО осуществлялась также при RT. Исследования проводились на экспериментальной установке с базовым давлением остаточных газов $4 \cdot 10^{-11}$ Torr. В экспериментах использовались электронная Оже-спектроскопия (ЭОС), дифракция медленных электронов (ДМЭ) и метод измерения контактной разности потенциалов, который, как известно, дает возможность измерять разность работ выхода $\Delta \varphi=\left(\varphi_{0}-\varphi\right)$ чистой поверхности какой-либо подложки $\left(\varphi_{0}\right)$ и работы выхода этой же подложки, покрытой адсорбированными слоями $(\varphi)$. 
В качестве подложек в экспериментах использовались кремниевые образцы $n$-типа (удельное сопротивление $1 \Omega \cdot \mathrm{cm})$. Перед началом экспериментов их поверхность очищалась кратковременными прогревами при $1500-1550$ К. Контроль чистоты образцов производился с помощью ЭОС. Для контроля структурного совершенства их поверхности использовался метод ДМЭ. Этот метод показал, что всегда после указанной температурной обработки на поверхности кремния $\operatorname{Si}(111)$ формируется сверхструктура $7 \times 7$.

Скорость осаждения иттербия обычно составляла 1 монослой (ML) в минуту. За $1 \mathrm{ML}$ атомов $\mathrm{Yb}$ на $\mathrm{Si}(111)$ была принята величина их поверхностной концентрации $7.84 \cdot 10^{14} \mathrm{~cm}^{-2}$, равная концентрации атомов $\mathrm{Si}$ на нереконструированной поверхности $\mathrm{Si}(111) 1 \times 1$.

Адсорбция газов на поверхность нанопленок иттербия производилась при давлении в вакуумной камере, равном $2 \cdot 10^{-7}$ Torr.

\section{3. Экспериментальные результаты и их анализ}

На рис. 1, $а$ приведены изотермы адсорбции для ряда толщин пленок иттербия. Зависимости приведены в координатах количество адсорбированных на пленках молекул СО - доза монооксида углерода. В качестве меры количества молекул СО на поверхности использовалась величина peak-to peak амплитуды Оже-пика кислорода $I(\mathrm{O})$ с энергией $503 \mathrm{eV}$, пропорциональная этому количеству. Доза монооксида углерода выражена в Лэнгмюрах $(\mathrm{L})\left(1 \mathrm{~L}=10^{-6}\right.$ Torr $\left.\cdot \mathrm{s}\right)$. Характерной особенностью приведенного на рис. 1, а семейства зависимостей является быстрый рост количества адсорбированных молекул при малых доза СО. При больших дозах этот рост довольно резко замедляется и процесс адсорбции переходит в стадию квазинасыщения.

Другой особенностью всего полученного семейства является то, что количество адсорбированных молекул при заданной дозе зависит от толщины пленок (размерный эффект). С ростом толщины это количество возрастает. Так, при дозе $400 \mathrm{~L}$ количество адсорбированных молекул при переходе от пленок толщиной $d=1 \mathrm{ML}$ к $16 \mathrm{ML}$ возрастает примерно в 2.5 раза. При малых толщинах пленок этот рост значителен. Однако при увеличении толщины $d$ он замедляется.

Для того, чтобы получить данные, которые дали бы возможность понять физическую природу процессов, которые обуславливают особенности изотерм адсорбции, приведенных на рис. 1, $a$, были изучены зависимости работы выхода нанопленок иттербия от доз монооксида углерода и от количества его молекул, адсорбированных на поверхности нанослоев при разных толщинах последних. Выбор указанных зависимостей был обусловлен тем, что знак изменения работы выхода дает важную информацию о том, в каком направлении происходит
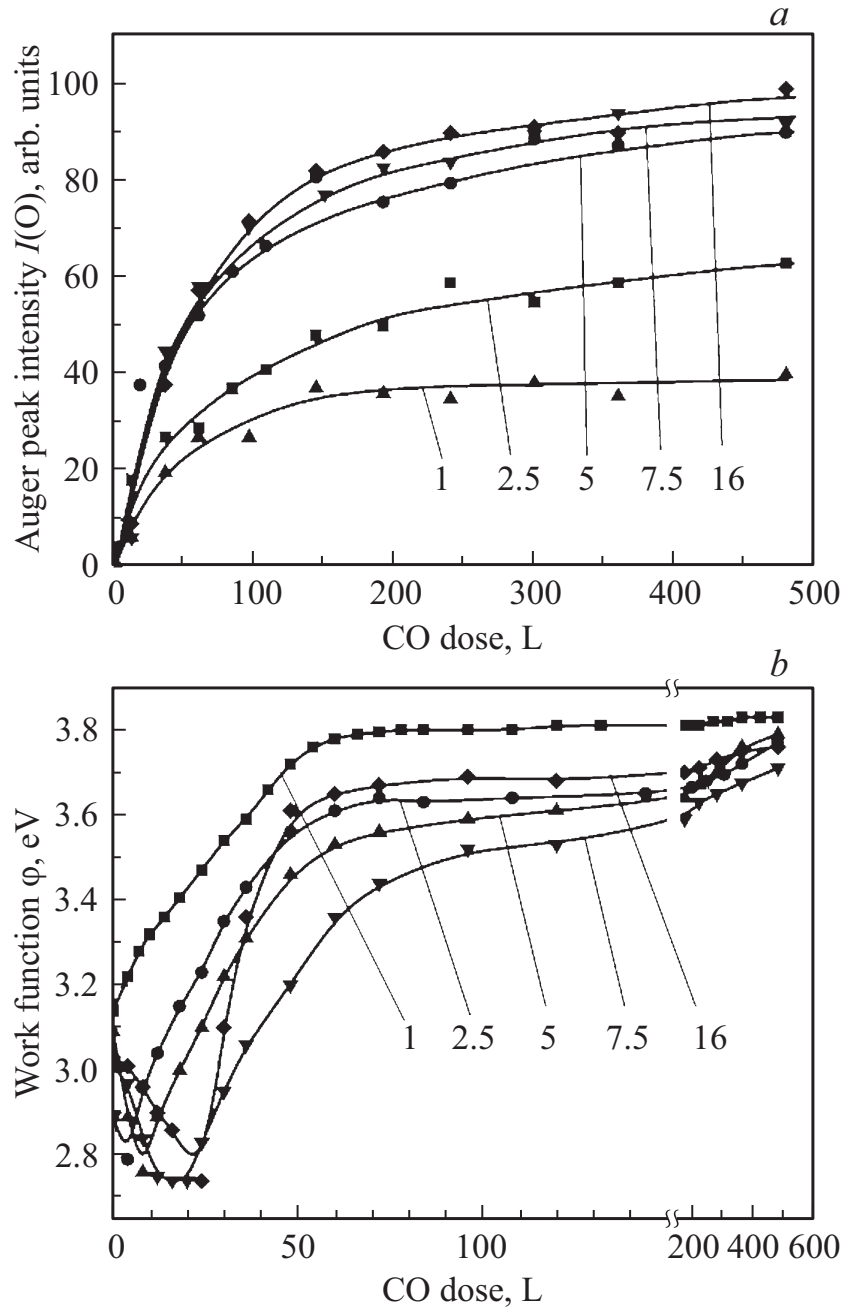

Рис. 1. (а) - зависимости количества адсорбированных молекул СО от дозы монооксида углерода (в Лэнгмюрах, L) для пленок иттербия разной толщины. По вертикальной оси отложена величина peak-to-peak оже-пика кислорода $I(\mathrm{O})$, пропорциональная количеству адсорбированных молекул СО. (b) - зависимости работы выхода $\varphi$ структур „слой адсорбированных молекул $\mathrm{CO}$ - нанопленка иттербия“ от дозы монооксида углерода (в Лэнгмюрах, L) для пленок разной толщины. На рис. $(a)$ и $(b)$ значения толщины пленок указаны в монослоях (ML) для каждой зависимости.

переход электронов при адсорбции монооксида углерода: из молекул в пленки или в обратном направлении. Такая информация чрезвычайно важна для понимания процессов, происходящих при формирования слоя адсорбированных молекул СО на поверхности нанопленок иттербия.

На рис. 1, $b$ приведены зависимости работы выхода от дозы СО. На рис. 2 приведены зависимости этой же величины от количества адсорбированных молекул CO. Из этих рисунков следует, что на начальных этапах адсорбции молекул работа выхода уменьшается на небольшую величину (около $0.3 \mathrm{eV}$ ), что свидетельствует о переходе электронов из молекул в пленки. 


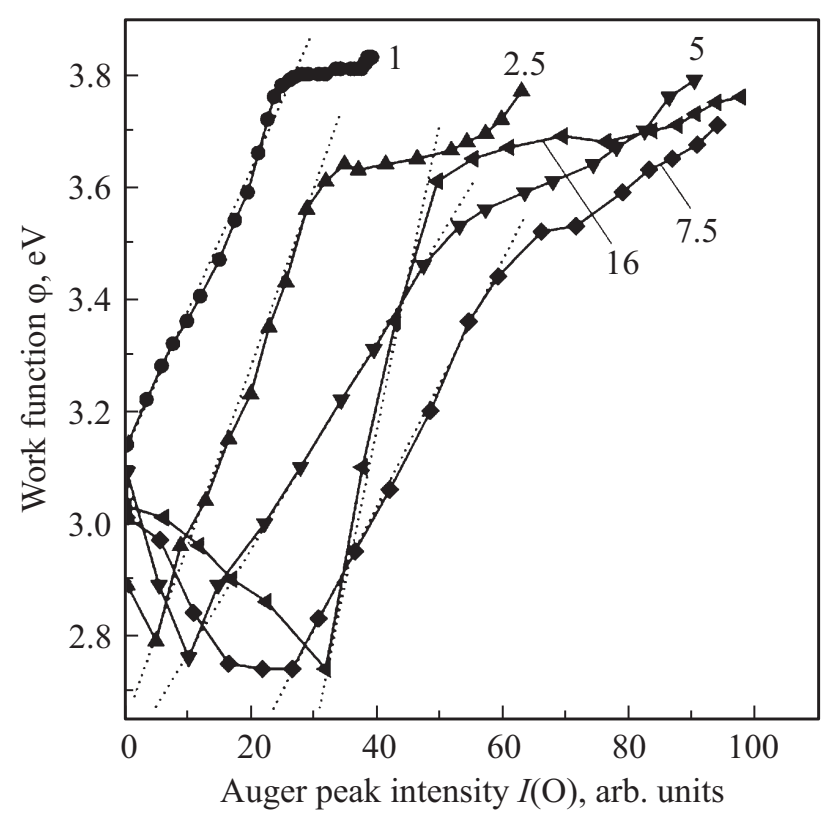

Рис. 2. Зависимости работы выхода $\varphi$ нанопленок иттербия от количества адсорбированных на их поверхности молекул СО. По оси абсцисс отложена величина peak-to-peak оже-пика кислорода $I(\mathrm{O})$, пропорциональная количеству адсорбированных молекул CO. Значения толщин пленок в монослоях (ML) показаны у каждой зависимости.

Достигнув минимума, работа выхода начинает линейно расти. Этот рост значителен. Он достигает величины, близкой к $1 \mathrm{eV}$. Рост работы выхода свидетельствует о том, что начался переход электронов из пленок в молекулы. После стадии линейного роста изменения работы выхода резко уменьшаются, несмотря на то, что поверхностная концентрация молекул СО продолжает расти. Последнее означает, что электронный обмен между иттербием и молекулами $\mathrm{CO}$ прекратился и что, следовательно, взаимодействие между теми и другими из стадии хемосорбции (сильная связь с подложкой) перешла в стадию физической адсорбции (слабая связь).

Для дальнейшего необходимо отметить еще один важный факт. Минимумы и линейные участки, на которых работа выхода растет, сдвигаются в сторону больших доз (рис. $1, b$ ) и больших поверхностных концентраций молекул СО (рис. 2) при увеличении толщины нанопленок иттербия (размерный эффект).

Для понимания физической природы полученных экспериментальных результатов и, в частности, описанных выше размерных эффектов необходимо рассмотреть механизм формирования адсорбционной связи молекул $\mathrm{CO}$ с поверхностью нанопленок иттербия, а также влияние этих молекул на электронное состояние металлического слоя. Это рассмотрение будет основано на результатах изучения адсорбции молекул монооксида углерода на поверхности макроскопических образцов никеля [12] и других $3 d$-металлов [13] и наших работах (предыдущие [9-11] и настоящая), в которых исследовалось вза- имодействие молекул $\mathrm{CO}$ и $\mathrm{O}_{2}$ с поверхностью пленок иттербия нанометровой толщины.

В работах, в которых изучалась адсорбция молекул СО на никеле, детально учитывались особенности их электронной структуры [12]. В частности, одной из таких особенностей является то, что из-за несовпадения атомных уровней кислорода и углерода связь в молекулах осуществляется только через $4 \sigma$ - и $1 \pi$-орбитали, тогда как вышележащая $5 \sigma$-орбиталь занята двумя несвязывающими неподеленными электронами, локализованными на углеродном конце молекулы.

Что же будет происходить при приближении этих молекул к поверхности никеля? Монооксид углерода при адсорбции остается в молекулярной форме, так как его замкнутые электронные оболочки чрезвычайно стабильны. Однако физической адсорбции не происходит. Вместо этого молекула ориентируется углеродным концом вниз и приобретает хемосорбционную энергию благодаря понижению $5 \sigma$-орбитали в результате образования связи с $d$-уровнем подложки. На химическом языке это означает, что молекула СО ведет себя как основание Льюиса, отдавая свои $5 \sigma$-электроны металлу. Кроме того, в процессе адсорбции незанятая $2 \pi$-орбиталь опускается ниже уровня Ферми. Последнее означает, что этот процесс сопровождается переходом электронов из никеля на эту орбиталь. Очевидно, что этот процесс будет сопровождаться ростом работы выхода структур вида „адсорбированный слой молекул $\mathrm{CO}$-никель“.

У иттербия в отличие от никеля $5 d$-зона лежит выше уровня Ферми и поэтому он является двухвалентным металлом. Однако, согласно данным работы [14] для перевода иттербия в трехвалентное состояние требуется затратить всего $9 \mathrm{ccal} / \mathrm{g}$.at $(0.4 \mathrm{eV})$. Этим, в частности, объяснятся то обстоятельство, что иттербий в целом ряде соединений является трехвалентным. Этот факт послужил основанием для предположения, высказанного авторами, что при хемосорбции (сильная связь с подложкой) некоторых молекул на поверхности нанопленок иттербия последний будет переходить из двухвалентного состояния в трехвалентное. Проведенные эксперименты полностью подтвердили это предположение. Было показано, что при адсорбции на поверхности нанопленок иттербия молекул кислорода и монооксида углерода происходит валентный переход $[10,11]$. Существенно то, что этот переход происходит в области поверхностных концентраций адсорбированных молекул, в которой наблюдается рост работы выхода. Было показано также, что при адсорбции молекулы своими двумя неподеленными электронами образуют с поверхностью иттербия донорно-акцепторную связь.

Очевидно, что при образовании донорно-акцепторной связи, как минимум, один электрон должен перейти из молекулы в пленку, как схематически показано на рис. 3. Этот переход будет сопровождаться уменьшением работы выхода системы „слой хемосорбированных молекул - нанопленка иттербия“. Как уже отмечалось, такое уменьшение на начальных этапах адсорб- 


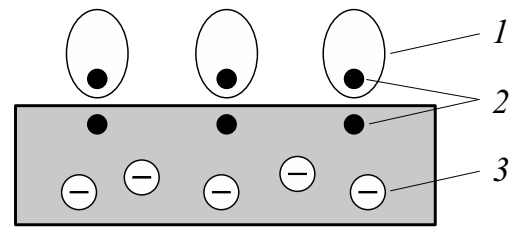

Рис. 3. Модель структур „слой хемосорбированных молекул $\mathrm{CO}$ - нанопленка иттербия“. 1 - адсорбированные молекулы CO; 2 - электроны, образующие донорно-акцепторную связь; 3 - электроны проводимости иттербия.

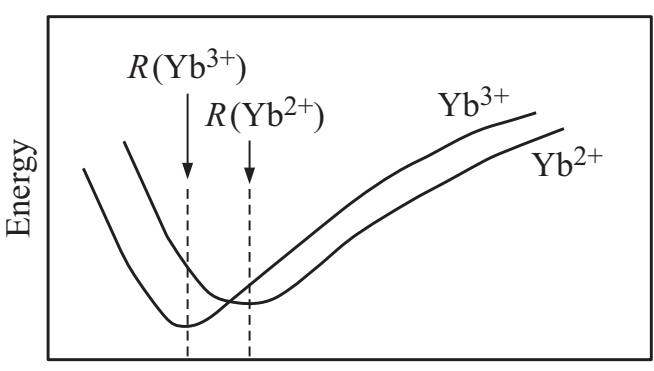

Distance between $\mathrm{Yb}$ atoms, $R$

Рис. 4. Энергия валентных электронов в зависимости от расстояния $R$ между атомами в нанопленках иттербия для двух- и трехвалентных состояний. $R\left(\mathrm{Yb}^{2+}\right)$ и $R\left(\mathrm{Yb}^{3+}\right)-$ равновесные расстояния для двух- и трехвалентного состояний.

ции молекул СО действительно наблюдается (рис. $1, b$ и 2). Это уменьшение сравнительно невелико, около $0.3 \mathrm{eV}$. Однако затем работа выхода начинает расти на значительную величину (около $1 \mathrm{eV}$ ). Этот рост означает, что происходит переход электронов из металла в слой адсорбированных молекул. Такой переход может быть обусловлен двумя причинами. Во-первых, локализованные на поверхности нанопленок электроны, формирующие донорно-акцепторную связь, кулоновскими силами взаимодействуют с электронами проводимости иттербия. Это отталкивающее взаимодействие будет возрастать при увеличении количества молекул $\mathrm{CO}$ на поверхности. Оно будет выталкивать электроны в молекулы. Во-вторых, свободные $2 \pi^{*}$-орбитали молекул $\mathrm{CO}$ в результате ухода неподеленных электронов в металл могут опуститься ниже уровня Ферми. Тогда выталкиваемые из металла электроны перейдут на эти орбитали. В результате работа выхода при увеличении количества молекул СО на поверхности будет расти.

Возмущение, оказываемое локализованными на поверхности электронами на состояние нанопленок, зависит от их толщины: с ростом последней оно будет ослабевать. Этот вывод следует из самых общих соображений. Действительно, когда толщина пленок достигнет макроскопических величин, влияние локализованных электронов станет ничтожно малым. Поэтому поверхностная концентрация молекул $\mathrm{CO}$, при которой начинается переход электронов в молекулы из пленок должна увеличиваться с ростом толщины последних (размерный эффект). Экспериментальные результаты, приведенные на рис. $1, b$ и 2 , полностью подтверждают этот вывод: при увеличении толщины нанопленок зависимости работы выхода от количества адсорбированных молекул смещаются вправо.

Отмеченный выше переход части электронов из пленок в молекулы может сопровождаться перестройкой зонной структуры иттербия. Действительно, указанный процесс приведет к уменьшению сил отталкивания между атомами $\mathrm{Yb}$, формирующих пленку, на малых расстояниях. Очевидно, что это приведет к уменьшению равновесного расстояния $R(\mathrm{Yb})$ в решетке и смещению энергетических уровней вниз (рис. 4). Это смещение может привести к тому, что $5 d$-уровень опустится ниже уровня Ферми. Тогда иттербий из двухвалентного металла трансформируется в трехвалентный $d$-металл. Как показывают полученные авторами результаты, такая трансформация действительно происходит на той стадии адсорбции молекул $\mathrm{CO}$, на которой наблюдается переход электронов из пленок в адсорбированные молекулы, т.е. на стадии роста работы выхода. И что очень существенно, увеличение валентности происходит не скачком, а постепенно по мере увеличения двухмерной концентрации молекул. В рамках сделанных выше предположений это означает, что валентность возрастает по мере уменьшения количества электронов в зоне проводимости иттербия, а также понижения и связанного с ним заполнения $5 d$-уровня.

Обращает на себя внимание тот факт, что величина полного изменения работы выхода на стадии ее линейного роста после минимума слабо зависит от толщины пленок. Кроме того, наклоны этих линейных участков (за исключением зависимости для $16 \mathrm{ML}$ ) близки друг к другу. Небольшие отличия обусловлены осцилляциями Фриделя, генерируемыми границей раздела $\mathrm{Yb}-\mathrm{Si}(111)$ [15]. Отмеченные особенности свидетельствуют о том, что при всех толщинах линейный рост работы выхода происходит в равных интервалах изменения поверхностной концентрации адсорбированных молекул. В принципе, это может быть связано с особенностями электронной структуры металлического иттербия. Так, может оказаться, что плотность состояний в $5 d$-зоне немонотонно зависит от энергии и компоненты этой зависимости существенно разнесены, как это показано на рис. 5. В этом случае при адсорбции молекул СО сможет опуститься ниже уровня Ферми только часть $5 d$-зоны. А так как адсорбция молекул после минимума связна с заполнением $5 d$-зоны, то при указанной ее структуре в сильносвязанных адсорбционных состояниях может находиться только определенное количество молекул. Следовательно, работа выхода при разных толщинах пленок может возрастать только на одну и ту же величину.

Сделанные выше предположения о том, что плотность состояний в $5 d$-зоне немонотонно зависит от энергии согласуется с результатами квантово-механических расчетов, выполненных в работе [16]. 


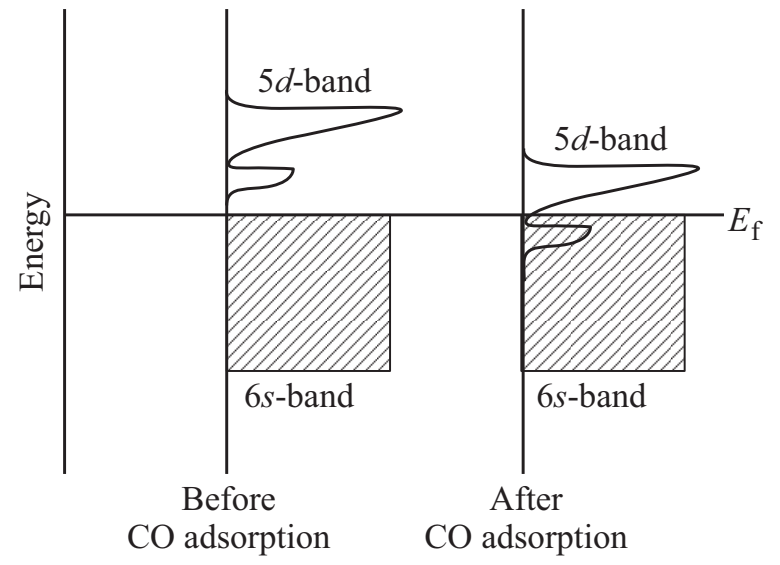

Рис. 5. Предполагаемый вид $5 d$-зоны иттербия и ее положение относительно уровня Ферми до адсорбции молекул СО на поверхности нанопленок (слева) и после (справа). Показаны только две компоненты. Однако их может быть больше.

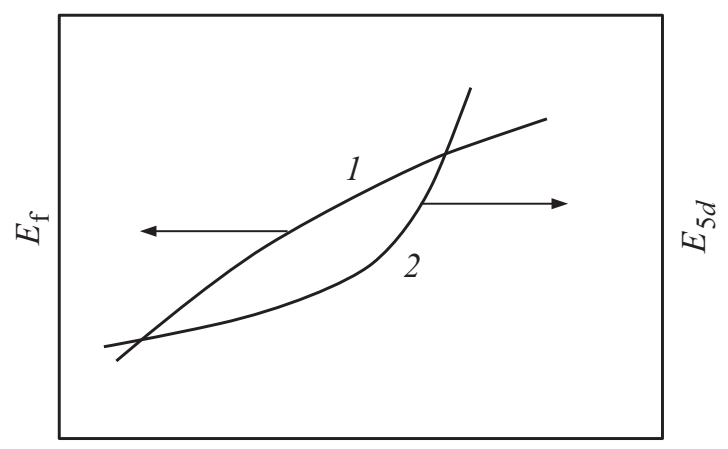

Density of electron gas, $n$

Рис. 6. Изменение энергии Ферми $E_{f}$ (кривая 1 ) и энергии $5 d$-уровня $E_{5 d}$ (кривая 2 ) при изменении плотности $n$ газа электронов проводимости в иттербии.

Существует, однако, другой, альтернативный вариант. Суть его состоит в том, что при перетекании части электронов проводимости из иттербия в молекулы уровень Ферми в металле будет понижаться. В приближении свободных электронов такой вывод вытекает из выражения для энергии Ферми $E_{f}[17]$

$$
E_{f}=\frac{h^{2}}{8 m}\left(\frac{3}{h} n\right)^{2 / 3}
$$

где $m$ - масса электрона, $n-$ плотность электронного газа. Зависимость величины $E_{f}$ от $n$, описываемая выражением (1), близка к линейной (рис. 6, кривая 1). Зависимость же положения $5 d$-уровня от $n$ неизвестна. Однако если эта зависимость имеет вид, показанный на рис. 6 (кривая 2), то сначала $5 d$-уровень при снижении плотности электронного газа понижается ниже уровня Ферми. Как уже было сказано, этот процесс сопровождается валентным переходом. Однако затем при некоторой критической плотности электронного газа этот уровень сравняется с уровнем Ферми, а затем превысит его.
Тогда переход $4 f$-электронов на $5 d$-уровень прекратится. Вместе с этим прекратится и адсорбция молекул СО в сильносвязанные состояния. Такой вывод следует из того, что указанная адсорбция на стадии роста работы выхода сопровождается переходом электронов проводимости из иттербия в молекулы. Необходимым условием такого перехода является процесс $4 f \rightarrow 5 d$. Прекращение последнего означает приостановку всех процессов, образующих рассматриваемую цепочку.

С помощью альтернативного варианта можно легко объяснить приведенные на рис. $1, b$ и 2 экспериментальные результаты, если предположить, что зависимости 1 и 2 рис. 6 являются универсальными. Такое предположение означает, что указанные зависимости при изменении толщины пленок не меняются, либо эти изменения слабо выражены. При таких условиях изменения работы выхода на стадии ее роста будут происходить в одних и тех же интервалах изменения плотности электронного газа. В структурах, исследованных в настоящей работе, это выразится в том, что рост работы выхода будет происходить в одних и тех же интервалах изменения поверхностной концентрации адсорбированных молекул. При этом сами эти интервалы при увеличении толщины пленок должны смещаться в сторону больших значений количества молекул на поверхности. Как уже было рассмотрено выше, это смещение обусловлено тем, что при увеличении толщины пленок необходимо большее количество локализованных на поверхности электронов, формирующих донорно-акцепторную связь молекул с поверхностью, для того, чтобы началось электростатическое выталкивание электронов проводимости из иттербия в адсорбированный слой.

Рассмотрение, проведенное при анализе результатов измерений работы выхода, дает возможность понять характерные особенности изотерм адсорбции, показанных на рис. $1, a$. Одна из их основных особенностей - это размерный эффект, т.е. зависимость количества адсорбированных молекул от толщины нанопленок иттербия при заданной дозе монооксида углерода. Сопоставляя результаты адсорбционных измерений с результатами исследований работы выхода можно сделать вывод, что указанный размерный эффект обусловлен кулоновским взаимодействием локализованных на поверхности электронов, формирующих донорно-акцепторную связь, с электронами проводимости иттербия и зависимостью этого взаимодействия от толщины пленок. Это отталкивающее электростатическое взаимодействие повышает, как уже отмечалось, энергию системы, ограничивая таким образом количество молекул, могущих адсорбироваться на поверхности нанопленок. Вклад электростатического взаимодействия в энергию системы „слой адсорбированных молекул $\mathrm{CO}$ - нанопленка“ с ростом толщины слоя иттербия уменьшается и это приводит к увеличению количества молекул $\mathrm{CO}$, которое при заданной дозе монооксида углерода могут адсорбироваться на поверхности. Таким образом, если при адсорбции на макроскопических подложках громадную 
роль играет геометрия поверхности и, в частности, количество адсорбционных мест, то в случае адсорбционных наносистем $\mathrm{CO}-\mathrm{Yb}-\mathrm{Si}(111)$ определяющим является электростатическое взаимодействие электронов, осуществляющих связь молекул с подложкой, с электронами проводимости иттербия. Сказанное означает, что в случае наносистем проявляются качественно новые закономерности адсорбционных явлений.

С помощью экспериментальных результатов, приведенных на рис. $1, a, b$ и 2, можно получить информацию, касающуюся коэффициента прилипания $s$ молекул СО к поверхности нанопленок на той стадии адсорбции, на которой этот процесс сопровождается валентным переходом иттербия из двухвалентного состояния $\mathrm{Yb}^{2+}$ в трехвалентное $\mathrm{Yb}^{3+}$. Важность такой информации обусловлена тем, что валентный переход индуцируется адсорбцией молекул, а коэффициент прилипания является одной из ее характеристик.

Коэффициент прилипания, как известно [18], входит в уравнение, связывающее скорость изменения поверхностной концентрации $d N / d t$ адсорбированных молекул с их потоком $I$ из газовой фазы на поверхность

$$
d N / d t=s I \text {. }
$$

Из (2) следует, что изменение величины $N$ за период времени $\Delta t=t_{2}-t_{1}$ при постоянном потоке будет равно

$$
\Delta N=I \int_{t_{1}}^{t_{2}} s(N) d t .
$$

Из рис. 1, $а$ следует, что в интервале доз от 0 до $50 \mathrm{~L}$ изотермы адсорбции близки к линейным (особенно для толщин пленок 5, 7.5 и $16 \mathrm{ML})$. кроме того, работа выхода на стадии ее быстрого роста (до 50L) также растет линейно. Эти данные дают основание предполагать, что коэффициент прилипания при указанных дозах от величины $N$ либо совсем не зависит либо эта зависимость слабая. Тогда приближенно выражение (3) может быть записано в более простом виде

$$
\Delta N=s I \Delta t .
$$

В (4) произведение $I \Delta t-$ это величина дозы за время $\Delta t$. Поток $I$ согласно кинетической теории газов равен [19]

$$
I=3.52 \cdot p /(M T)^{1 / 2},
$$

где $p$ - давление газа (Torr), $M$ - молекулярный вес, $T$ - температура. Из (4) следует, что при комнатной температуре и при давлении монооксида углерода $2 \cdot 10^{-7}$ Torr, при котором производились измерения, величина $I$ равна $3.83 \cdot 10^{13} \mathrm{~cm}^{-2}$. Тогда при дозе $50 \mathrm{~L}$, количество молекул, испытавших соударение с $1 \mathrm{~cm}^{-2}$ поверхности пленок, равно $I \cdot \Delta t=1.9 \cdot 10^{16}$. Абсолютное значение величины $\Delta N$ в описываемых экспериментах не определялось. Однако уверенно можно утверждать, что

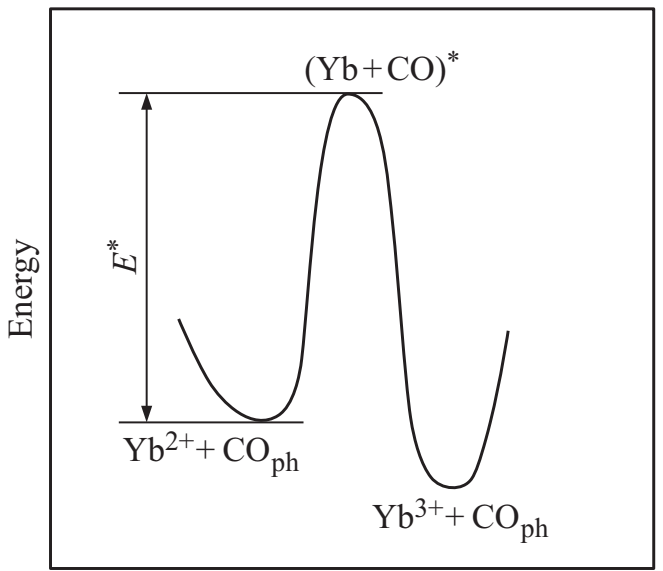

Reaction coordinate

Рис. 7. Изменение потенциальной энергии в процессе валентного перехода $\mathrm{Yb}^{2+} \rightarrow \mathrm{Yb}^{3+}$, индуцируемого адсорбцией молекул $\mathrm{CO} .(\mathrm{Yb}+\mathrm{CO})^{*}$ - активированное состояние (переходный комплекс). $E^{*}-$ энергия активации перехода. Символами $\mathrm{CO}_{\text {ph }}$ и $\mathrm{CO}_{\mathrm{ch}}$ обозначены молекулы, находящиеся в состояниях физадсорбции и хемосорбции соответственно. Горизонтальная ось - координата реакции валентного перехода.

оно не может превышать величины $10^{15} \mathrm{~cm}^{-2}$. Следовательно для коэффициента прилипания, определенного как отношение $s=\Delta N /(I \Delta t)$, для дозы $50 \mathrm{~L}$ будет справедлива оценка $s \leq 5 \cdot 10^{-2}$, свидетельствующая о том, что коэффициент прилипания мал.

Результаты проведенных оценок дают основание предполагать, что на стадии линейного роста работы выхода процесс адсорбции молекул СО на поверхности нанопленок иттербия носит двухступенчатый характер. На первой из них (стадия физадсорбции) молекулы связываются с поверхностью слабыми силами. На этой стадии донорно-акцепторная связь не образуется. И поэтому переход электронов из пленок в молекулы не происходит. Переход ко второй стадии, сопровождающийся образованием донорно-акцепторной связи (стадия хемосорбции), перетеканием электронов из пленок в молекулы и изменением валентности иттербия, требует преодоления некоего активационного барьера $E^{*}$, как это показано на рис. 7. Можно предполагать, что этот барьер и определяет величину коэффициента прилипания $s$, который, исходя из проведенного рассмотрения, следует записать в виде

$$
s=s_{0} \cdot \exp \left(-E^{*} / k T\right) .
$$

Наличие активационного барьера для адсорбции приводит к тому, что величина коэффициента прилипания много меньше единицы.

\section{4. Заключение}

Исследована адсорбция монооксида углерода на пленках иттербия нанометровой толщины (от 1 до 16 монослоев). Пленки создавались путем напыления иттербия 
на монокристаллические кремниевые подложки $\mathrm{Si}(111)$ при комнатной температуре.

Изучались изотермы адсорбции, т. е. зависимости количества адсорбированных молекул СО от дозы монооксида углерода. Прослежены также аналогичные зависимости для работы выхода нанопленок иттербия. И наконец, были исследованы зависимости работы выхода от поверхностной концентрации молекул СО. С помощью изотерм адсорбции обнаружен размерный эффект. Суть его состоит в том, что количество адсорбированных молекул при заданной дозе зависит от толщины пленок: с ростом последней возрастает количество адсорбата на поверхности. Размерный эффект обнаруживается также и при сравнении работ выхода структур вида $\mathrm{CO}-\mathrm{Yb}-\mathrm{Si}(111)$ отличающихся друг от друга только толщиной нанослоя металла. Указанные эффекты обусловлены, в конечном счете, кулоновским взаимодействием локализованных на поверхности электронов, осуществляющих связь молекул СО с нанопленками, и электронами проводимости иттербия. Это зависящее от толщины пленок взаимодействие выталкивает электроны проводимости из иттербия в адсорбированные молекулы, что приводит к изменению зонной структуры металла. В результате иттербий при достаточно большой концентрации молекул на поверхности нанопленок из двухвалентного состояния переходит в трехвалентное. Полученные результаты указывают на качественное отличие процессов адсорбции на нанопленках иттербия от аналогичных процессов на макроскопических образцах. В случае последних большую роль играет поверхность образцов, в частности, ее структура. При адсорбции же на нанопленках иттербия громадную, определяющую роль играет их объем. Такие свойства пленок нанометровой толщины обнаружены впервые.

Количественный анализ изотерм адсорбции показал, что коэффициент прилипания при адсорбции молекул СО мал. На стадии адсорбции, на которой рост количества молекул СО на поверхности сопровождается увеличением работы выхода и валентным переходом, его величина меньше $5 \cdot 10^{-2}$. Столь малое значение может быть обусловлено наличием кулоновского баръера для перехода электронов с $4 f$-уровня атомов $\mathrm{Yb}$ на их $5 d$-уровень. Этот переход является составной частью процесса адсорбции молекул СО на поверхности пленок иттербия.

\section{Список литературы}

[1] А.М. Шикин. Формирование, электронная структура и свойства низкоразмерных структур на основе металлов. ВВМ. Спб (2011). 432 c.

[2] G. Cao, Y. Wang. Nanostructures and nanomaterials: synthesis, properties, and applications. World Scientific. (2011). V. 2. $581 \mathrm{p}$.

[3] J.-W. He, W.K. Kuhn, L.-W. Leung, D.W. Goodman. J. Chem. Phys. Chem. 93, 7463 (1990).
[4] J.-W. He, C.A. Estrada, J.S. Corneille, M.-Ch. Wu. Surf. Sci. 261, 164 (1992).

[5] M. Rauh, B. Heping, P. Wissmann. Appl. Phys. A 61, 587 (1995).

[6] E.L. Wilson, Q. Chen, W.A. Brown, G. Thornton. J. Phys. Chem. C 111, 14215 (2007).

[7] P. Jakob, A. Schlapka. Surf. Sci. 601, 1556 (2007).

[8] F. Voigts, F. Bebensee, S. Dahle, K. Volgmann, W. MausFriedrichs. Surf. Sci. 603, 40 (2009).

[9] М.В. Кузьмин, М.В. Логинов, М.А. Митцев. ФТТ 51, 795 (2009).

[10] Д.В. Бутурович, М.В. Кузьмин, М.В. Логинов, М.А. Митцев. ФТТ 57, 1822 (2015).

[11] М.А. Митцев, М.В. Кузьмин, М.В. Логинов. ФТТ 58, 2054 (2016).

[12] Э. Зенгуил. Физика поверхности. / Пер. с англ. Мир, М. (1980). $536 \mathrm{c}$.

[13] E.W. Plummer, W.R. Salaneck, J.S. Miller. Phys. Rev. B 18, 1673 (1978).

[14] K.S. Gschneidner. Less-Common Met. 17, 13 (1969).

[15] М.В. Кузьмин, М.А. Митцев. ФТТ 56, 1397 (2014).

[16] Y. Kubo. J. Phys. F 17, 383 (1987).

[17] Ч. Киттель. Введение в физику твердого тела. Наука, М. (1978). $791 \mathrm{c}$.

[18] К. Оура, В.Г. Лившиц, А.А. Саранин, А.В. Зотов, М. Катаяма. Введение в физику поверхности. Наука, М. (2006). $490 \mathrm{c}$.

[19] S. Dushman. Scientific Foundationof Vacuum Technique. John Willey \& Sons, Inc. N.Y., London (1962). 715 p.

Редактор Т.Н. Василевская 